\title{
"External Fixation Followed By Casting Compared To External Fixation Followed By Open Reduction Internal Fixation"- Which Method To Choose For Complicated Open Grade 3b Pilon Fractures?
}

\author{
Dr Ashish Garg ${ }^{1}$, Dr B Lokesh ${ }^{2}$ \\ 1 MS Orthopedics Junior Resident, Mmimsr Mullana \\ 2 MS Orthopedics Junior Resident, Mmimsr Mullana \\ DOI: 10.29322/IJSRP.10.10.2020.p10669 \\ http://dx.doi.org/10.29322/IJSRP.10.10.2020.p10669
}

\begin{abstract}
Management of Pilon fractures continue to be unsolved mystery for Orthopaedic surgeons even in today's modern era. Earlier, majority of these fractures were to be treated by conservative management only for want of improved surgical techniques and implants resulted in wound complications and poor functional outcome in terms of range of motion at ankle joint, pain and associated joint stiffness. Majority of the patients land up with ankle arthrodesis and amputations especially in 43-C3 fractures. With advancement and improvisation of our knowledge in anatomy and biomechanics of the distal tibia and with improved surgical techniques, now the trend has been shifted from conservative towards operative approach to manage such fractures showing dramatic improvements functionally. Despite all the efforts, dilemma still persists for the correct method to choose for management of such injuries. In order to vein off such confusion, a comparison has been studied between two cases of open grade 3B Pilon fractures managed by two different methods.
\end{abstract}

Index Terms- Pilon fracture, External fixator, Ovadia Beals criteria.

\section{INTRODUCTION}

$\mathrm{T}$ The word "Pilon" is a French terminology meaning a "pestle". Etienne Destot, a French Radio-anatomist, first used the term 'Pilon' in 1911(1) to describe the anatomical region $5 \mathrm{~cm}$ proximal to the ankle joint. Describing the mechanism of fractures of this region, Destot stated that the talus acts as a "pestle" during the injury. On sustaining high velocity trauma of the distal part of tibia, Pilon fracture occurs as a result of axial loading which drives the talus into the distal tibia smashing the distal tibial articular continuity. This results in impaction of the comminuted fragments of metaphyseal bone up to approximately $8-10 \mathrm{~cm}$ proximal from the distal tibial articular surface. Pilon fracture affects weight bearing articular surface of distal tibia and commonly affects males (57-65\%) between 35-40 years of age.(2) Road traffic accidents $(45.5 \%)$ closely followed by the fall from height are the two most frequent mechanisms of injury(2). High velocity tibial Pilon fractures remains a challenging task for the treating orthopaedic surgeons since the past several decades which is evident from the fact that various methods are there for the management of such injuries but none has been proven to be superior to others. In 1959, Jergesen asserted that treatment of comminuted complicated Pilon fractures was impossible with open reduction internal fixation method resulted in an era of cast immobilisation as a sole mode of treatment for these debilitating injuries(2,3). It was in mid-1960's when AO/ASIF first time had come up with general guidelines for the treatment of such intraarticular fractures of distal tibia which had changed the whole way of treatment method of these kind of fractures by paying attention towards articular congruity management, metaphyseal defect filling, length and rotational alignment by fixing fibula and fixation of metaphysis to tibia diaphysis and allowing early return of function of the joint(2)(4). Since then various studies had been conducted for obtaining the fruitful results in terms of posttraumatic functional outcome of such injuries but none has been universally standardized.

Present comparative study between two similar cases according to Gustilo Anderson classification is an attempt to elucidate the actual postoperative functional outcomes as per Ovadia Beals scoring system, to assess the complications associated with them and to conclude which method should be chosen for such fractures by treating one case with open reduction internal fixation and other with casting after applying external fixator primarily.

\section{CASE PRESENTATION}

In this prospective comparative study, two cases have been included having open grade $3 \mathrm{~B}$ fractures presented to the emergency department of MM Institute of Medical sciences and research, Mullana, Ambala and managed by department of Orthopaedics. Informed and written consent will be taken from the patients participating in the study beforehand.

\section{Case 1: AO 43-C3 Open grade 3B Fracture}

A 25-year male patient Jonny brought to the emergency department of MM Institute of Medical sciences and research, Mullana on $8^{\text {th }}$ September 2019 with alleged history of road traffic 
accident. On presentation, proper history had been taken and on initial examination no other injury found.

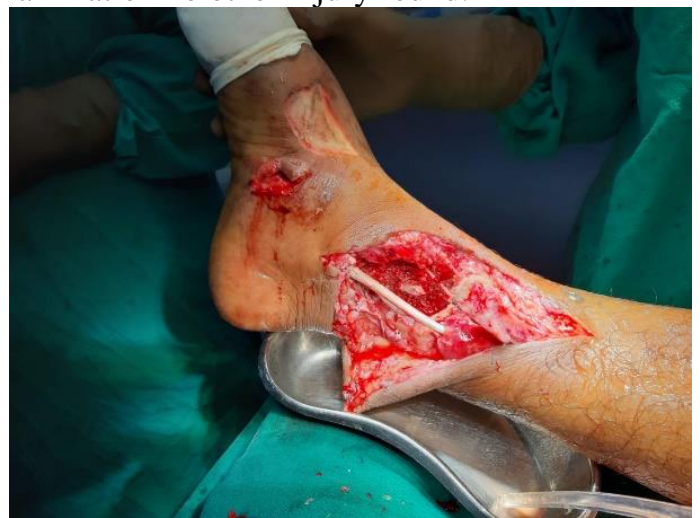

Fig 1. Image showing crush injury distal aspect of right leg medial side with bone protruded out of the wound and tendons exposed and degloving of the soft tissue over medial malleolus.

At presentation, there was crush injury right lower limb with tibial bone fragment protruded out of the wound of approximately $12 \mathrm{~cm} \times 7 \mathrm{~cm}$ along with tendon stretched over the medial malleolus. After through wash with saline and betadine, stay suture applied, empirical antibiotics were started and radiographs obtained of the injured limb which was suggestive of intraarticular tibial fracture (Pilon fracture) with metaphyseal comminution, Varus mal alignment and bone loss along with ipsilateral fracture fibula. There was no neurosensory deficit elicited and after primary management, POP slab given and planned for debridement and external fixation.

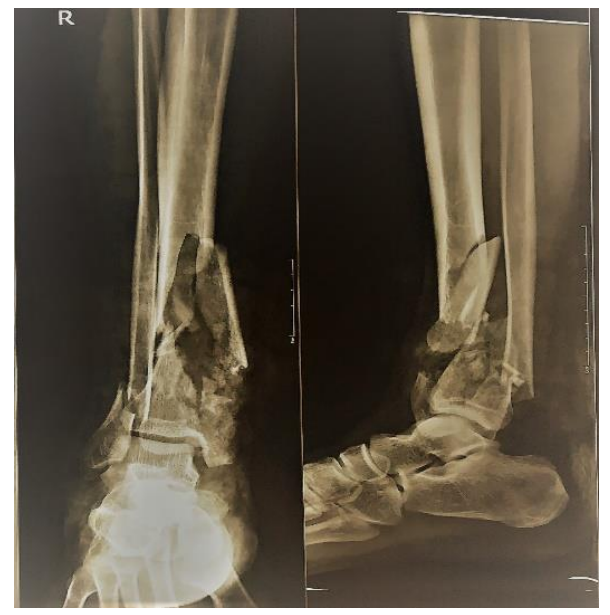

Fig 2. Radiograph showing intraarticular tibial fracture (Pilon fracture) with metaphyseal comminution and fracture fibula just above syndesmosis.

Within 24 hours of admission, debridement was done and External fixator applied. Patient started on empirical antibiotics (cephalosporins) and all baseline investigation send. Daily dressing done and monitoring done by infection markers such as CBC, ESR and CRP values. Daily dressing was done for 1 week but inflammatory markers remained increased and after 1-week serous discharge started oozing out of the wound from which swab was send for pus culture and sensitivity. MRSA was found in pus culture report for which vancomycin was started for 10 days and monitoring done by repeat $\mathrm{CBC}, \mathrm{ESR}$ and CRP. After 10 days of antibiotic and daily dressing wound become healthy, inflammatory markers decreased and patient planned for discharge with necessary antibiotics and advised to follow up in OPD after 4 weeks.

After 4 weeks of injury, patient right leg radiograph was taken to assess the status of fracture.

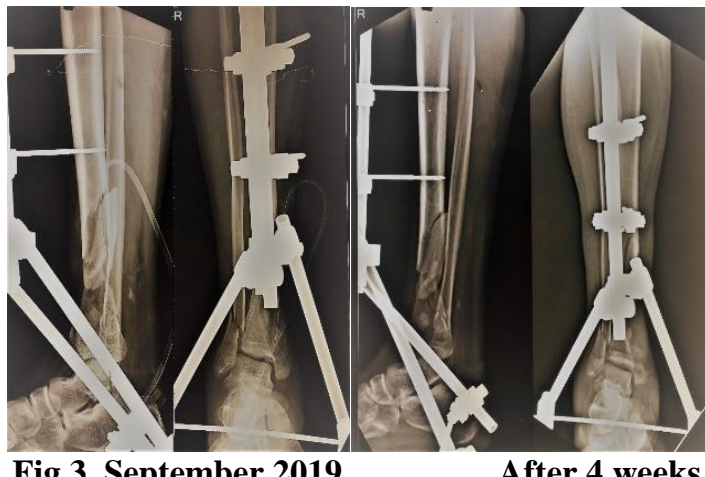

Fig 3. September 2019

After 4 weeks

Radiograph after Debridement and External fixator for temporary fracture stabilization. After 6 weeks of regular follow up, external fixator removed and above knee POP slab applied for 2 weeks and every alternate day dressing being done for medial side wound to heal completely. After total 8 weeks of injury again radiograph taken to assess the fracture. Since there was bone gap at the fracture site due to bone loss, fracture union was not possible without further intervention. Inflammatory markers investigation repeated after every 2 weeks to observe the status of infection. Meanwhile, active toe movement exercises continued. After 8 weeks of injury, inflammatory markers came within normal range and patient planned for definitive plate fixation along with autogenous bone grafting.

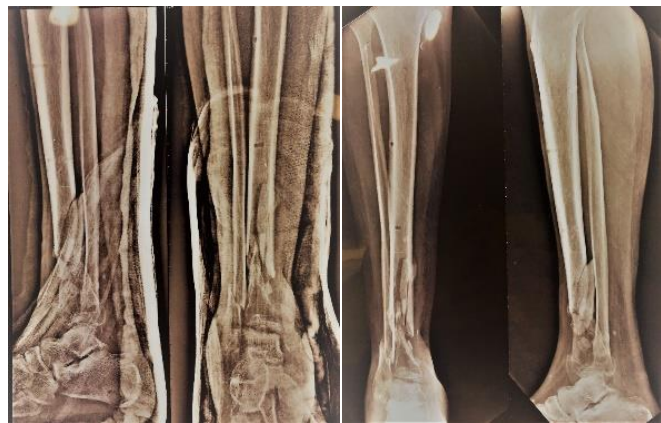

Fig 4. After 6 weeks After 8 weeks

Before plating of the distal tibia, CT with 3D reconstruction of the right leg was taken in order to understand the fracture fragments anatomy more clearly and accordingly surgical approach, type of implant and technique to be used were planned. 


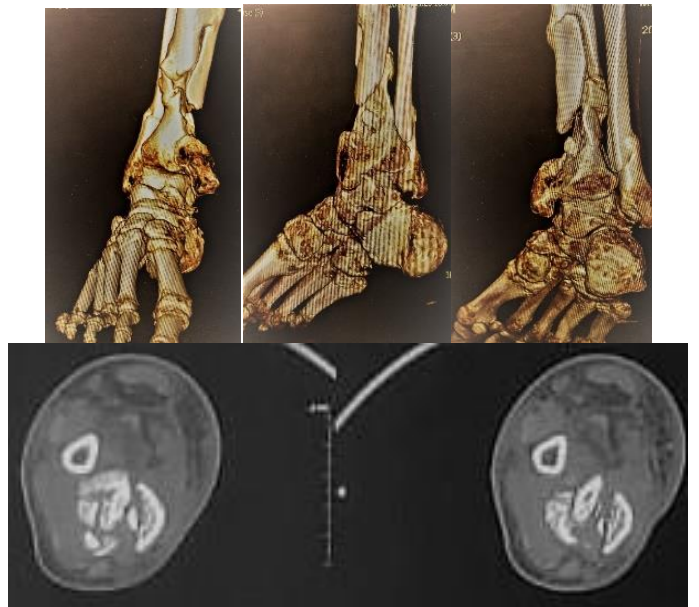

Fig 5. Axial CT section at tibial plafond showing multiple fracture fragments.

CT images clarified that there was a bone gap of approximately $3-4 \mathrm{~cm}$ and ankle mortice was unstable due to numerous fracture fragments at the articular surface of tibia. Since, fibula was also fractured therefore to reduce both bones, anterolateral approach was used for plating. Bone graft was taken from iliac crest as distal metaphyseal region of tibia is corticocancellous in nature and iliac crest bone is also of similar composition.

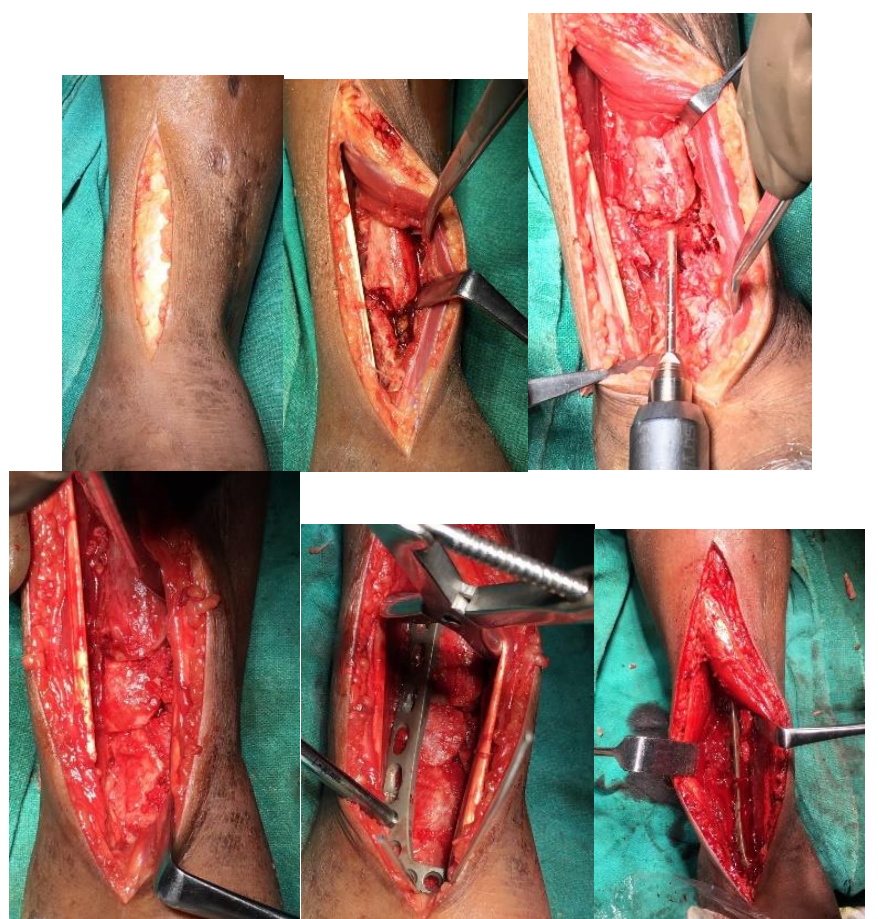

Fig 6. Intra operative images of anterolateral approach for distal tibia plating with bone grafting.

Postoperatively, first dressing was done on day 2 and empirical antibiotics were started for 1 week postop. Radiograph was taken on second day to assess the fracture reduction, position of bone graft and articular congruency. Limb was elevated and strictly immobilized. Next dressing was done on postop day 5 which went uneventful and patient was planned for discharge and advised for regular follow up in OPD for further management after 4 weeks. Patient was also advised for dressing after every 2 days and active toe exercise till next 4 weeks.

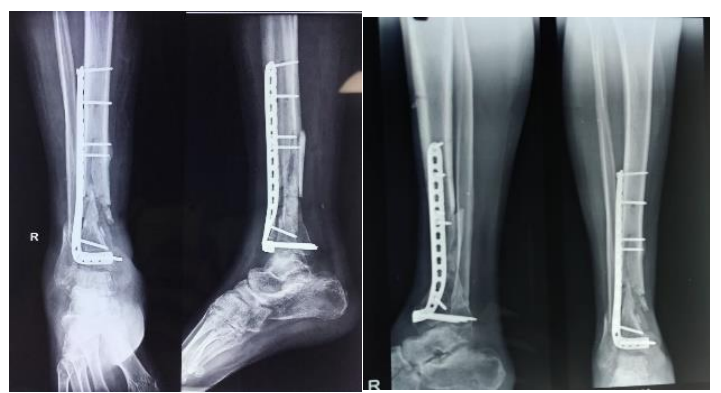

Fig 7. After 8 weeks After 12 weeks

Postoperative x-rays showed bone graft in place, articular congruency maintained but Varus mal-alignment persists. Patient advised toe exercises to continue and after 6 weeks of plating, partial weight bearing started with walker. Fracture showed formation of callus after 6 weeks of partial weight bearing upon which full weight bearing started and fracture union occur around 24 weeks after injury. Radiographs were taken after 6 months and then after 1 year of injury as per follow up protocol.

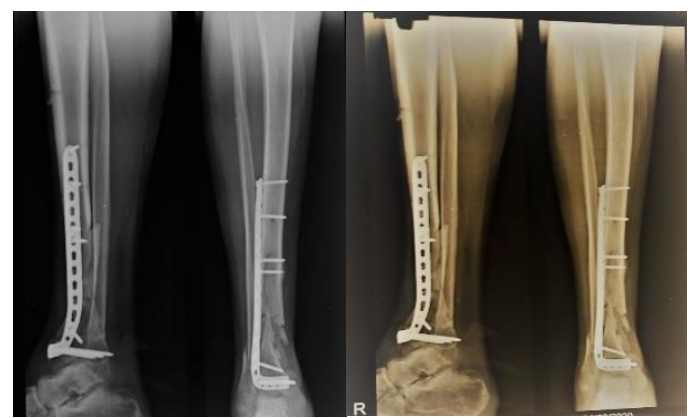

Fig 8. Radiograph after 6 months, 1 year

After 1 year of injury, patient was having mild pain at the ankle joint only after strenuous activity otherwise he was able to returned to his previous level of activity. There was no limping and ankle joint range of motion was around 40 degree of plantarflexion and 15 degree of dorsiflexion.

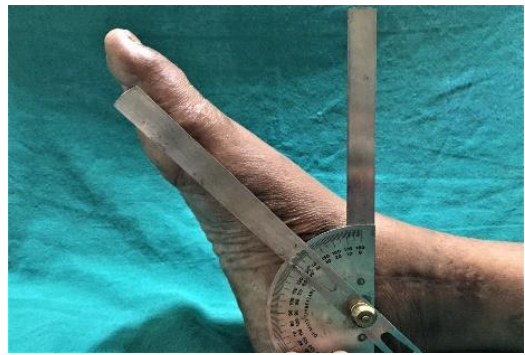

Fig 9. Ankle joint range of motion around 40 degree of plantarflexion 


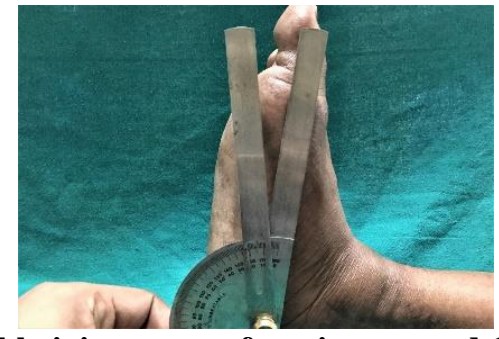

Fig 10. Ankle joint range of motion around 15 degree of dorsiflexion

Case 2: AO 43-C2 Open grade 3B Fracture

A 40-year female patient Ravinder Kaur brought to the emergency department of MM Institute of Medical sciences and research, Mullana on $4^{\mathrm{TH}}$ May 2019 with alleged history of road traffic accident. On presentation, proper history had been taken and on initial examination patient also had un-displaced fracture of bilateral pubic rami.

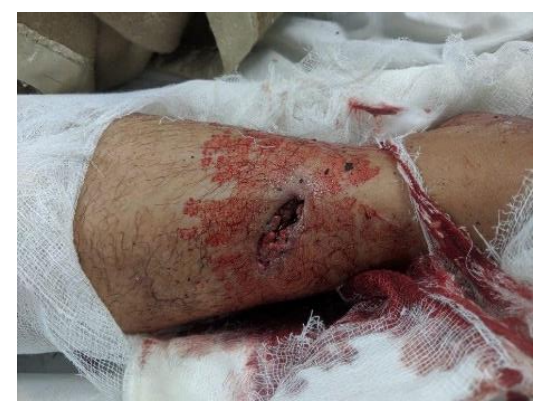

Fig 11.

At presentation, there was open wound at right lower limb anterior aspect of approximately $6 \mathrm{~cm} \mathrm{x} 3 \mathrm{~cm}$ with fracture exposed outside environment. No neurosensory deficit elicited. After through wash with saline and betadine, stay suture applied, empirical antibiotics were started and radiographs obtained of the injured limb which was suggestive of intraarticular tibial fracture (Pilon fracture) with metaphyseal comminution along with ipsilateral fracture fibula. After primary management, POP slab given and planned for debridement and external fixation.

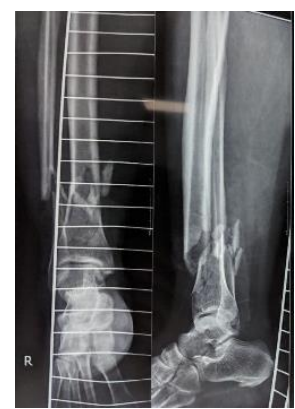

Fig 12.

Within 24 hours of admission, debridement was done and External fixator applied. Patient started on empirical antibiotics (cephalosporins) and all baseline investigation send. Daily dressing done for 7 days and monitoring done by infection markers such as CBC, ESR and CRP values. After $7^{\mathrm{TH}}$ day, inflammatory markers repeated which was remained increased and condition of wound wasn't healthy and serosanguinous discharge started coming out of wound therefore it was opened for dressings and wound swab was send for pus culture and sensitivity.

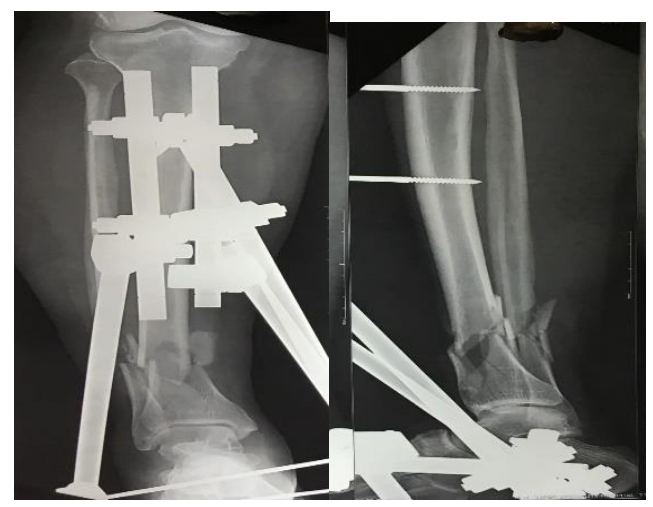

Fig 13. September 2019

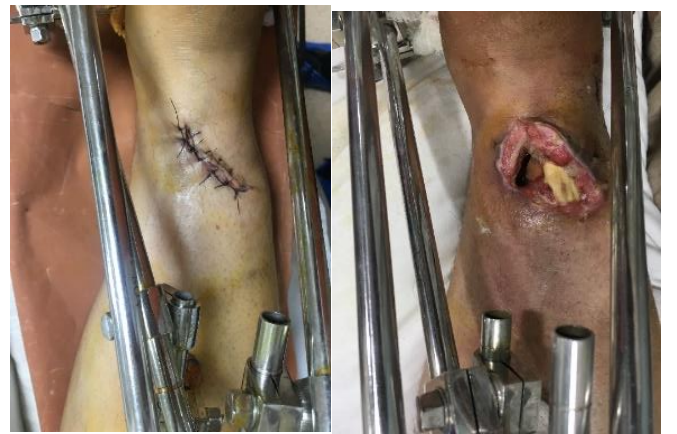

Fig 14. Escherichia coli and Methicillin resistant staphylococcus aureus (MRSA) infection resulting in opening of sutures and daily dressing.

Culture sensitivity suggestive of Escherichia coli and MRSA infection for which Tobramycin and chloramphenicol antibiotics started as per sensitivity index. Daily dressing was done for 2 weeks after which repeat inflammatory markers and culture send. Reports suggestive of absence of any micro-organisms. Inflammatory markers value decreased but serous discharge still persists. In order to close wound, Negative pressure wound therapy (NPWT) started with the help of Vacuum assisted closure (VAC). After 10 days, healthy granulation tissue came and wound now become ready to accept flap graft.

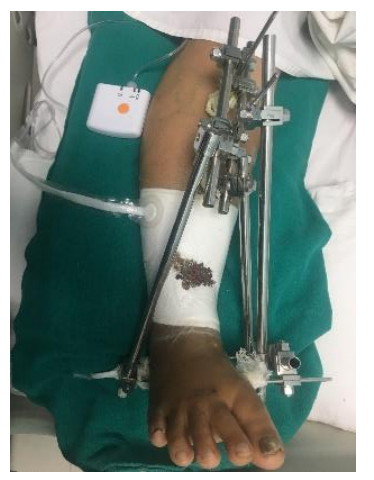

Fig 15. Negative pressure wound therapy (NPWT) started with the help of Vacuum assisted closure (VAC). 


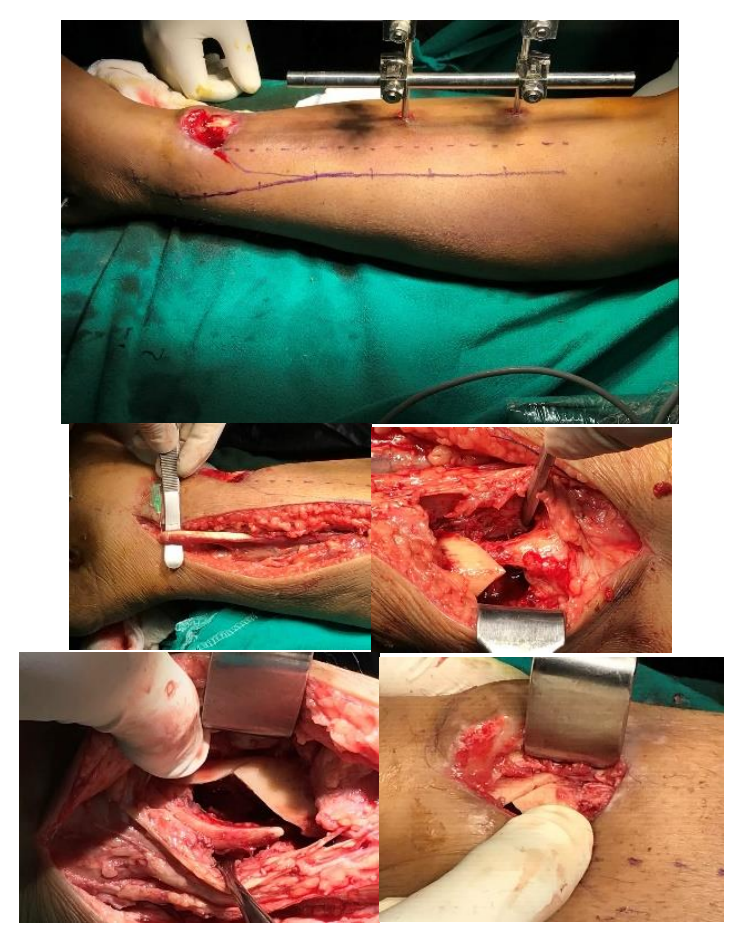

Fig 16. Intra operative images of flap grafting with fracture

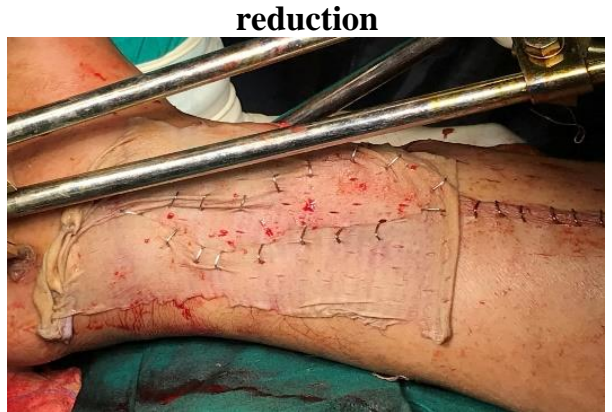

Fig 17. After 4 weeks of injury, repeat radiograph was taken to assess the fracture reduction and anatomy of osseous

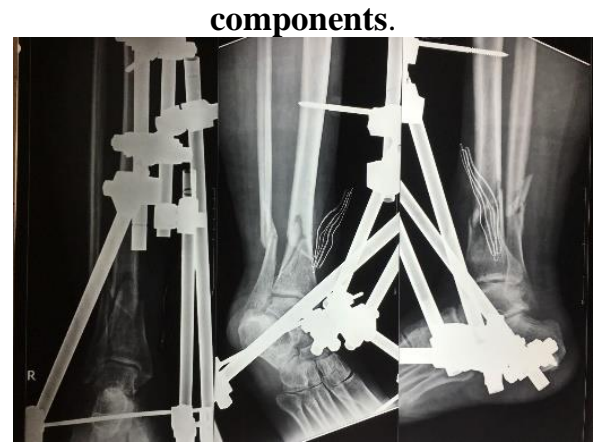

Fig 18. October 2019

Radiograph obtained after 4 weeks showed maintenance of articular congruency and tibial shortening of less than $1 \mathrm{~cm}$ with valgus mal-alignment. Metaphyseal comminution was there and ankle joint stability was questionable. Every alternate day dressing being done and wound condition assessed with help of inflammatory markers. CT with $3 \mathrm{D}$ reconstruction performed for better assessment of anatomy of impacted fracture fragments and further surgical approach and technique for definitive plate fixation.

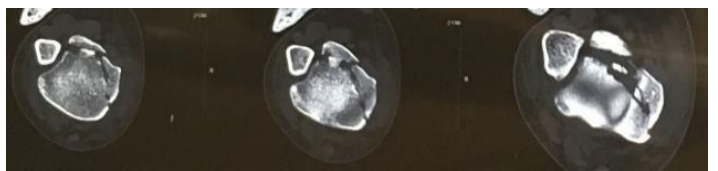

Fig 19. Axial CT section showing intra articular fracture with mild comminution.

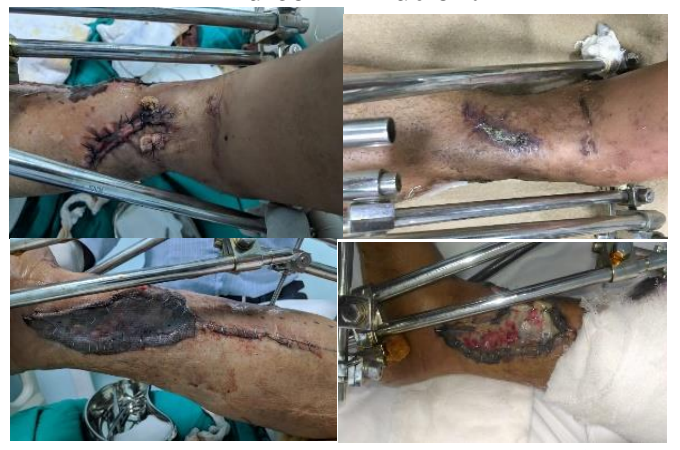

Fig 20. Comparison between dressings of the flap and skin graft in 4 weeks interval

After 4 weeks of flap grafting, anterior wound healed satisfactorily but medial side (skin graft site) showed graft necrosis with serous discharge. Repeat inflammatory markers were within normal limits. Amid peculiar vascular supply of soft tissue over ankle joint, thin soft tissue coverage over bone and poor flap graft conditions even after 4 weeks of grafting, it was decided to change plan from plating of distal tibia towards conservative management of the fracture with external fixator only followed by casting. Repeat radiograph was taken for assessment of fracture.

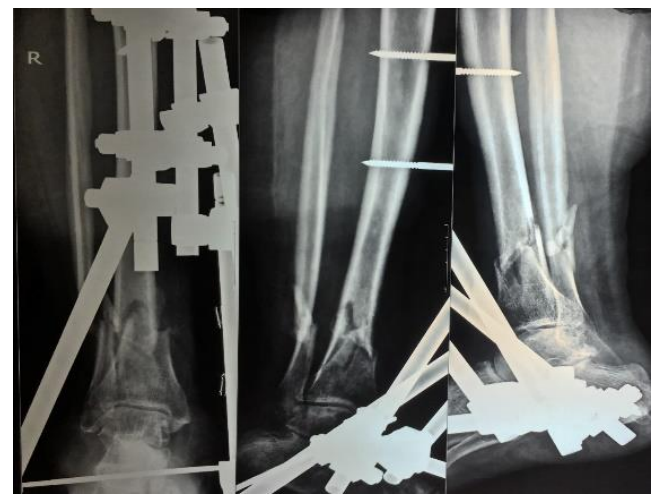

Fig 21. November 2019

Radiograph showed maintenance of articular congruency and mild callus formation and valgus mal-alignment. Clinically, wound at graft site become healthy and flap had been successfully accepted by the graft site and pain was also decreased. Therefore, patient was discharged with External fixator in situ and advised to follow up after 4 weeks in OPD. Active toe exercises advised to the patient. 


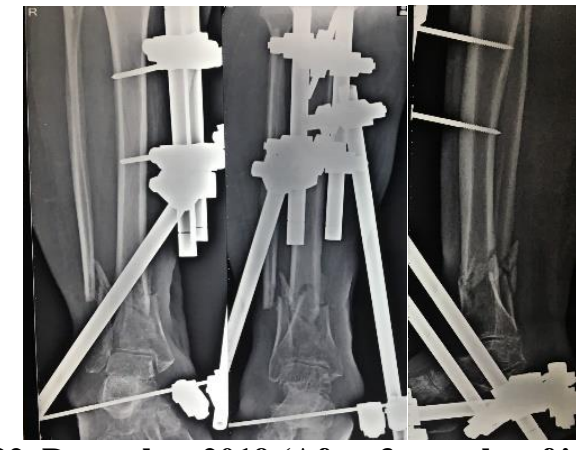

Fig 22. December 2019 (After 3 months of injury)

After 4 weeks repeat radiograph was taken showing callus formation and ankle mortice maintained. Tibial shortening of less than $1 \mathrm{~cm}$ persists and valgus mal-alignment of less than 5 degree was elicited. Clinically, patient pain was improved and wound was healed. After considering present status of fracture healing and patient clinical condition, External fixator was removed and above knee cast applied. Patient advised to follow up after 3 months in OPD.

After 6 months of injury, patients repeat radiograph was taken which shows abundant callus formation to allow patient for partial weight bearing with walker.

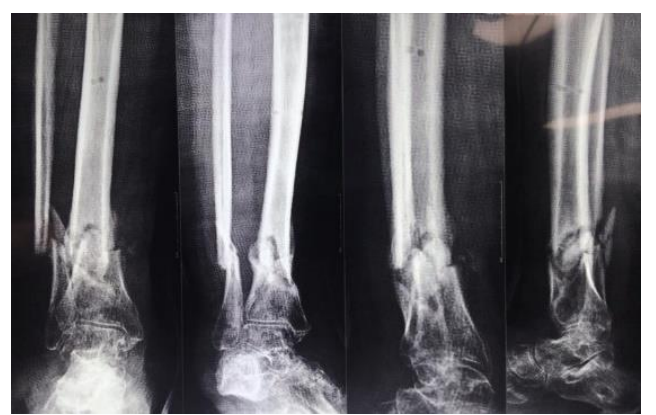

Fig 23. March 2020 (After 6 months of injury)

Above knee cast converted to patellar tendon bearing cast (PTB Cast) and patient allowed partial weight bearing with help of walker. Clinically, pain was improved form moderate to mild severity for which occasional analgesics were required. Again after 6 weeks of partial weight bearing patient was follow up with repeat radiograph showing fracture union after which PTB cast removed and full weight bearing allowed and advised to follow up after 1 year.

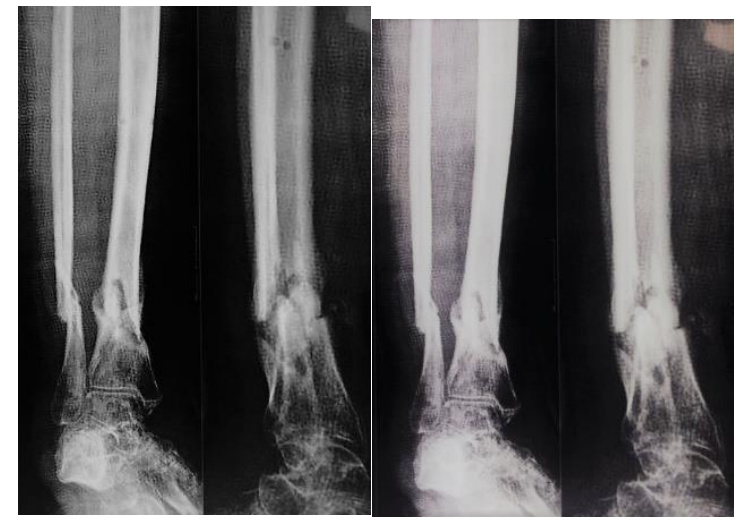

Fig 24. 30 weeks of injury

1 year

After 1 year of injury, patient was having mild pain at the ankle joint only after strenuous activity otherwise he was able to returned to his previous level of activity. There was no limping and ankle joint range of motion was around 25 degree of plantarflexion and 5 degree of dorsiflexion.

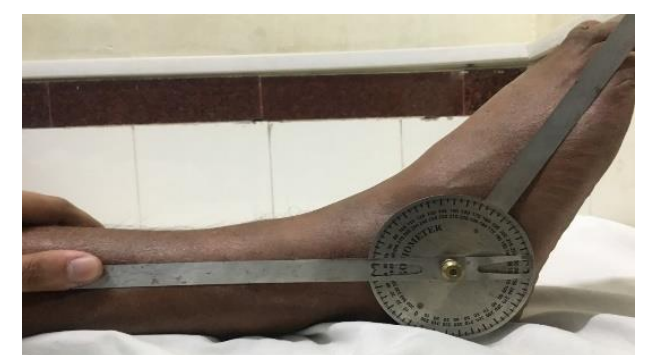

Fig 25. Ankle joint range of motion around 25 degree of plantarflexion

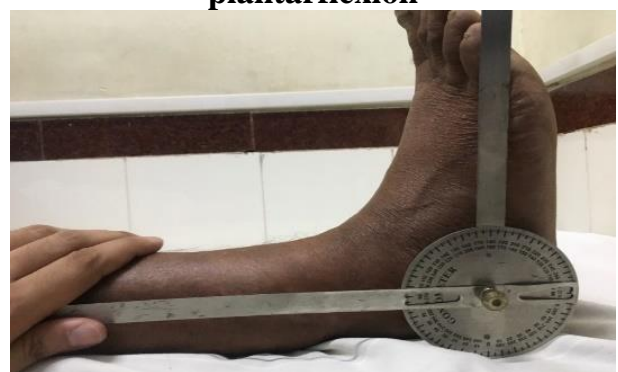

Fig 26. Ankle joint range of motion around 5 degree of dorsiflexion

\section{RESULTS}

In our study, results were analysed by Ovadia and Beals clinical scoring system. This criterion not only gives objective parameters for the assessment of the outcome but also included the subjective questionnaire which would be answered by the patient so that the results remained unbiased throughout. Data obtained were summarized in a tabular format for quick access. 


\begin{tabular}{|c|c|c|}
\hline PARTICULARS & CASE 1 & CASE 2 \\
\hline Age /Sex & 25yr /Male & 40yr /Female \\
\hline $\begin{array}{l}\text { Mechanism of } \\
\text { Injury }\end{array}$ & $\begin{array}{l}\text { Road traffic } \\
\text { accident }\end{array}$ & $\begin{array}{l}\text { Road traffic } \\
\text { accident }\end{array}$ \\
\hline $\begin{array}{l}\text { Limb involved } \\
\text { (side) }\end{array}$ & Right & Right \\
\hline $\begin{array}{l}\text { Type of Fracture } \\
\text { (Open) }\end{array}$ & $\begin{array}{l}\text { Gustilo } \\
\text { Anderson } \\
\text { 3B }\end{array}$ & $\begin{array}{l}\text { Gustilo } \\
\text { Anderson 3B }\end{array}$ \\
\hline $\begin{array}{l}\text { AO Classification } \\
\text { of fracture }\end{array}$ & $43-\mathrm{C} 3$ & $43-\mathrm{C} 2$ \\
\hline Associated Injury & $\begin{array}{l}\text { Fracture } \\
\text { Fibula } \\
\text { (Right side) }\end{array}$ & $\begin{array}{l}\text { Fracture } \\
\text { Fibula (Right } \\
\text { side), Fracture } \\
\text { B/L Pubic } \\
\text { Rami } \\
\end{array}$ \\
\hline Treatment & $\begin{array}{l}\text { Debridement } \\
\text { with } \\
\text { External } \\
\text { fixation, } \\
\text { ORIF with } \\
\text { Plating. } \\
\end{array}$ & $\begin{array}{l}\text { Debridement } \\
\text { with External } \\
\text { fixation, Cast } \\
\text { immobilization }\end{array}$ \\
\hline $\begin{array}{l}\text { Period of } \\
\text { Immobilization }\end{array}$ & 14 weeks & 24 weeks \\
\hline $\begin{array}{l}\text { Partial weight } \\
\text { bearing }\end{array}$ & 8 weeks & 6 weeks \\
\hline Union time & 24 weeks & 30 weeks \\
\hline $\begin{array}{l}\text { Secondary } \\
\text { procedure }\end{array}$ & $\begin{array}{l}\text { Bone } \\
\text { grafting \& } \\
\text { secondary } \\
\text { closure }\end{array}$ & $\begin{array}{l}\text { Flap \& skin } \\
\text { grafting, } \\
\text { secondary } \\
\text { closure }\end{array}$ \\
\hline Complications & $\begin{array}{l}\text { Deep } \\
\text { infection, } \\
\text { delayed } \\
\text { union. }\end{array}$ & $\begin{array}{l}\text { Deep } \\
\text { infection, } \\
\text { delayed union. }\end{array}$ \\
\hline
\end{tabular}

Table 1: Tabular representation of the data collected from two cases

Since both the cases had Gustilo Anderson grade 3B open fractures with one case had $\mathrm{AO} 43-\mathrm{C} 3$ fracture and other with $\mathrm{AO}$ 43-C2 fracture, case 1 had been treated with two staged protocol that is initially debridement done with application of external fixator along with intravenous antibiotics. Continuous monitoring was done with CBC, ESR AND CRP values. After counts decreased and wound appear healthy, external fixator removed and open reduction internal fixation was planned whereas in case 2 , initial debridement done with application of external fixator which regularly scrutinized with serial radiographs and later on converted into (conservative method) below knee cast. Pt has been followed up at $3^{\mathrm{RD}}$ month, $6^{\mathrm{TH}}$ month and 1year postoperatively. The final results analysed as per Ovadia Beals scoring system to compare the functional outcome of both the patients with similar open grade 3B fracture treated by two different modality and summarized in tabular form.

Table 2: Tabular representation of final results as per Ovadia Beals scoring system.

\begin{tabular}{|l|l|l|}
\hline $\begin{array}{l}\text { OVADIA BEALS } \\
\text { SYSTEM }\end{array}$ & CASE 1 & CASE 2 \\
\hline $\begin{array}{l}\text { OBJECTIVE } \\
\text { SCORING }\end{array}$ & & \\
\hline $3^{\mathrm{RD}}$ month & Fair & Fair \\
\hline $6^{\mathrm{TH}}$ month & Good & Fair \\
\hline $1^{\mathrm{ST}}$ year & Good & Fair \\
\hline $\begin{array}{l}\text { SUBJECTIVE } \\
\text { SCORING }\end{array}$ & & \\
\hline $3^{\mathrm{RD}}$ month & Poor & Fair \\
\hline $6^{\mathrm{TH}}$ month & Fair & Good \\
\hline $1^{\mathrm{ST}}$ year & Good & Good \\
\hline
\end{tabular}

Above-mentioned results showed that after long time has elapsed, as per Objective criteria, there were difference between the functional outcome of two cases where patient treated with plate fixation had "Good" outcome as compared with patient managed with casting. On the other hand, as per subjective criteria, there was no difference between them. Subjectively, there was continuous improvement in the case operated with plate fixation whereas the patient treated with cast immobilization showed improvement of only one step ahead. The ankle joint range of motion is taken with the help of goniometer.

\section{Discussion}

Pilon fractures, being an uncommon injury, represent approximately $7-10 \%$ of total tibial fractures and $1-5 \%$ of total lower limb fractures(2). There is lack of methodical research regarding the management and outcome of these fractures in the published literature but since the incidence of this injury is rising in present world scenario amidst the rise in occurrence of road traffic accidents(5), there is renewed interest in the surgical fraternity for studies to better manage these injuries.

Pilon fracture affects weight bearing articular surface of distal tibia and commonly affects males (57-65\%) between 35-40 years of age.(6) Road traffic accidents (45.5\%) closely followed by the fall from height are the two most frequent mechanisms of injury(2). The management of high velocity tibial Pilon fractures remains an unsolved mystery and challenging task for the treating orthopaedic surgeons since the past several decades. Earlier, most authors concluded that majority of the distal tibial fractures were to be treated conservatively and were not amenable to open reduction and internal fixation due to intra articular extension of the fracture segment, comminution at weight bearing surface and unavailability of instrumentation options and various surgical approaches what we have now a days which changes the final postoperative results dramatically. In today's modern era, with the availability of improved surgical techniques and implants, there is not a single fixation method for all types of Pilon fractures that we encountered.

Suggested principles behind definitive fixation are:

1) Maintaining articular congruency and stability. 
2) Restoration of length and preventing mal-alignment.

3) Management of bone stock either primarily or by late definitive fixation and grafting.

4) Minimize the soft tissue damage.

5) Early postoperative restoration of joint functional range.(7)

Optimal functional results depend upon the mechanism of injury and accordingly choice of implants selected on the basis of fracture pattern and soft tissue condition. Similar statement has been verified in present comparative study where in plate fixation case, due to open avulsed injury of the soft tissue of the right ankle, initially external fixation was done after proper debridement of the wound in order to avoid infections and afterwards plate fixation planned with bone grafting.

Factors indicating bad prognosis are:

1) Complete intra-articular comminution ( $\mathrm{AO} 43 . \mathrm{C} 3$ and Reudi Allgower type 3)

2) Injury to talus

3) Excessive soft tissue compromise

4) Articular mal-reduction

5) Unstable fracture fixation

6) Postoperative surgical site infection.(8)

There are certain flaws that prevails resulting in mal reduction and poor functional outcome especially in comminuted 43-C3 fractures where achieving articular congruency within acceptable range play a pivotal role in successful management.

Basic difficulties that arises in the management of pilon fractures are:

1) Tendency of re-displacement of the fracture fragments after swelling has been subsided mainly in spiral or comminuted fractures upon cast application.

2) Distal third tibia has precarious blood supply therefore chances of delayed union are very high.

3) Since knee and ankle joint are in same parallel axis, functional and cosmetic deformities occur if rotational malalignment is not corrected.(9)

Two most common pitfalls in the management of such fractures intra operatively-

1) Failure to reorganize the position of TillauxChaput Tubercle.

2) Failure to recognize the lateral-disruption fractures.

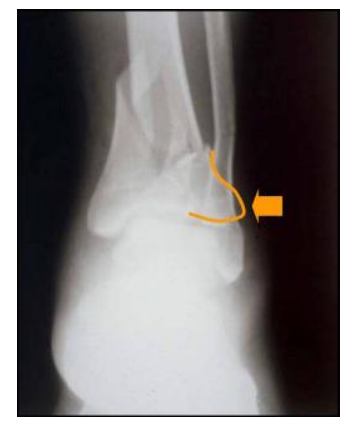

This publication is licensed under Creative Commons Attribution CC BY

http://dx.doi.org/10.29322/IJSRP.10.10.2020.p10669
"Disruption" is defined as more than $2 \mathrm{~mm}$ of incongruity at the articular surface or mal-alignment more than 10 degrees in any plane. The TILLAUX-CHAPUT TUBERCLE highlighting above is the only marker available for the assessment of correct anatomical reduction of the fractures involving complete articular surface.

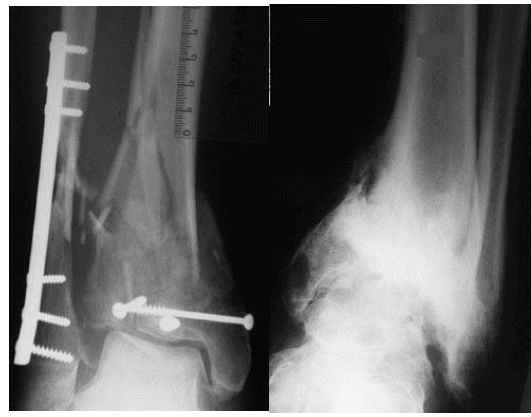

Radiographs exemplifying failure to recognize the lateraldisruption fractures after initial fixation showing the longterm consequence of onset of osteoarthritis with Varus deformity.

Thus, restoration of the normal talofibular relationship in lateral-disruption fractures is of immense importance in achieving normal alignment and function of ankle joint postoperatively. This restoration will automatically be going to reduce the lateral tibial fragments which paved the way for fixation of the remaining articular surface.

Surgical intervention and complications go hand in hand. In this case, despite all the efforts to avoid infections, some part of bone at the distal tibia become necrosed due to exposure to the external environment and deep infection which got over in due course of antibiotics. Along with bone grafting, secondary wound closure was done due to excessive wound oedema initially. Similarly, in second case, initially debridement and external fixation was done followed by application of below knee cast because of deep wound infection which was treated with alternate day debridement's and vacuum assisted closure (VAC) was done as there was continuous discharge from the wound. In study conducted by Rafael Carbonell-Escobar et al.(10) in 2017 reported $13.04 \%$ infections, $7.6 \%$ skin necroses, $10.86 \%$ nonunions and $13.04 \%$ posttraumatic osteoarthritis of ankle joint. Similar results have been published in the study conducted by Michael Sirkin and Roy Sanders showing 31\% incidence of infection and $10 \%$ cases diagnosed with osteomyelitis(11).

The treatment goal for intra articular fracture distal end tibia is stabilization, achievement of articular congruity and early restoration of motion at the ankle joint so that the chances of post traumatic ankle osteoarthritis and stiffness can be minimized and patient can have better functional outcome. It depends upon patient demographics and comorbidity, fracture morphology, articular incongruity, mechanism of injury, amount of fragment stability, reducibility and displacement which varies patient to patient. From this study, we have observed that optimum results depend more on the timing of surgery (staged procedure) and condition of soft tissue healing rather than type of instrumentation used. 


\section{CONCLUSION}

Pilon fracture is considered to be a constellation of numerous fractures that usually comprised of distal tibial metaphyseal fracture, fracture of medial malleolus, fracture of anterior tibial margin and posterior surface of tibia. Having multiple components and peculiarities of the anatomy and biomechanics at the distal end of tibia, successful management of such fracture continues to be a challenging task which requires consideration towards all these regions meticulously. Apart from bone fragments stabilization, timing of surgery, surgical procedure and paying respect to soft tissues are equally necessary components in order to achieve fruitful functional outcome. On comparing two different method of treatment in present study, we concluded that none of the method was superior to other. Since, as per subjective criteria, both of them had "Good" functional outcome despite the fact that both of the fracture gone into delayed union which highlights the immense importance of making decision according to condition pertaining to the particular injury and not to remain stick to single protocol for every open fracture.

\section{REFERENCES}

[1] Helfet DL, Koval K, Pappas J, Sanders RW, DiPasquale T. Intraarticular \&quot;pilon\&quot; fracture of the tibia. Clin Orthop Relat Res. 1994 Jan;(298):221-8.

[2] Calori GM, Tagliabue L, Mazza E, de Bellis U, Pierannunzii L, Marelli BM, et al. Tibial pilon fractures: which method of treatment? Injury. 2010 Nov 1;41(11):1183-90.

[3] Wheeless' Textbook of Orthopaedics [Internet]. [cited 2020 Aug 22]. Available from: http://www.wheelessonline.com/ortho/tibial_
[4] Pugh KJ, Wolinsky PR, McAndrew MP, Johnson KD. Tibial pilon fractures: A comparison of treatment methods. In: Journal of Trauma - Injury, Infection and Critical Care. Lippincott Williams and Wilkins; 1999. p. 937-41.

[5] Tarkin IS, Clare MP, Marcantonio A, Pape HC. An update on the management of high-energy pilon fractures. Vol. 39, Injury. Injury; 2008. p. $142-54$.

[6] Boraiah S, Gardner MJ, Helfet DL, Lorich DG. High association of posterior malleolus fractures with spiral distal tibial fractures. Clin Orthop Relat Res. 2008;466(7):1692-8.

[7] Jacob N, Amin A, Giotakis N, Narayan - Badri, Nayagam - Selvadurai, Trompeter AJ. Management of high-energy tibial pilon fractures.

[8] Luo TD, Pilson H. Fracture, Pilon. StatPearls. StatPearls Publishing; 2018.

[9] Siddiqui YS, Siddiqui YS, Jain JK, Zahid M, Abbas M, Sabir A Bin, et al. Minimally Invasive Percutaneous Plate Osteosynthesis (Mippo) in Distal Tibial Fractures - A Prospective Study from Developing Nation. J Trauma Treat. 2014 May 30;s2(01):1-5.

[10] Carbonell-Escobar R, Rubio-Suarez JC, Ibarzabal-Gil A, RodriguezMerchan EC. Analysis of the variables affecting outcome in fractures of the tibial pilon treated by open reduction and internal fixation. J Clin Orthop Trauma. 2017;8(4):332-8.

[11] Sirkin M, Sanders R. The treatment of pilon fractures. Orthop Clin North Am. 2001;32(1):91-102.

\section{AUTHORS}

First Author - Dr ASHISH GARG, MS ORTHOPEDICS JUNIOR RESIDENT, MMIMSR MULLANA, ashishgarg30011993@gmail.com

Second Author - Dr B LOKESH, MS ORTHOPEDICS JUNIOR RESIDENT, MMIMSR MULLANA, bandilokesh3@gmail.com 